\title{
Ensino de Suporte Básico de Vida para estudantes do Ensino Médio: estudo quase- experimental
}

\author{
Teaching Basic Life Support for High School students: quasi-experimental study \\ Enseñanza de Soporte Vital Básico para estudiantes de Secundaria: estudio casi-experimental
}

Recebido: 24/09/2021 | Revisado: 03/10/2021 | Aceito: 06/10/2021 | Publicado: 10/10/2021

Flávia Helena Pereira

ORCID: https://orcid.org/0000-0001-9331-7020 Instituto Federal de Educação, Ciência e Tecnologia do Sul de Minas Gerais, Brasil E-mail: flavia.pereira@ifsuldeminas.edu.br

Danilo Donizetti Trevisan

ORCID: https://orcid.org/0000-0002-6998-9166 Universidade Federal de São João del Rei, Brasil E-mail: ddtrevisan@gmail.com

Ariane Ranzani Rigotti

ORCID: https://orcid.org/0000-0002-7440-7044 Universidade de São Paulo, Brasil E-mail: arianerrigotti@gmail.com

Fabrine Aguilar Jardim Pinto

ORCID: https://orcid.org/0000-0002-0798-5987

Universidade de São Paulo, Brasil

E-mail: fabrineaguilar@gmail.com

Daiane Nascimento Vilela

ORCID: https://orcid.org/0000-0002-5138-2382 Instituto Federal de Educação, Ciência e Tecnologia do Sul de Minas Gerais, Brasil

E-mail: dai-vilela@hotmail.com

Ana Cláudia Faria de Pimenta

ORCID: https://orcid.org/0000-0003-2575-4645 Instituto Federal de Educação, Ciência e Tecnologia do Sul de Minas Gerais, Brasil

E-mail: anaclaudia1991@ hotmail.com

Silmara Aparecida Ferreira Coelho

ORCID: https://orcid.org/0000-0003-0574-8723 Instituto Federal de Educação, Ciência e Tecnologia do Sul de Minas Gerais, Brasil

E-mail: silmara.coelho@bol.com.br

Juliano de Souza Caliari

ORCID: https://orcid.org/0000-0002-3021-1138 Instituto Federal de Educação, Ciência e Tecnologia do Sul de Minas Gerais, Brasil

E-mail: juliano.caliari@ifsuldeminas.edu.br

Heloisa Turcatto Gimenes Faria

ORCID: https://orcid.org/0000-0002-4052-4189

Instituto Federal de Educação, Ciência e Tecnologia do Sul de Minas Gerais, Brasil

E-mail: heloisa.faria@ifsuldeminas.edu.br

José Antônio Dias Garcia

ORCID: https://orcid.org/0000-0002-4024-3045 Instituto Federal de Educação, Ciência e Tecnologia do Sul de Minas Gerais, Brasil

Universidade José do Rosário Vellano, Brasil

E-mail: jose.garcia@ifsuldeminas.edu.br

Cloves Gomes de Carvalho Filho

ORCID: https://orcid.org/0000-0001-7026-4253

Instituto Federal de Educação, Ciência e Tecnologia do Sul de Minas Gerais, Brasil

E-mail: cloves.filho@ifsuldeminas.edu.br

\section{Resumo}

Introdução: o conhecimento de medidas de Suporte Básico de Vida favorece para o atendimento em Parada Cardiorrespiratória, com vistas à redução na taxa de mortalidade. Objetivo: analisar o efeito do treinamento em Suporte Básico de Vida para estudantes do ensino médio. Metodologia: estudo quase-experimental, realizado em março de 2019, em uma instituição de ensino público federal, com estudantes do ensino médio. Os dados sociodemográficos e as questões acerca do conhecimento em Suporte Básico de Vida foram coletados a partir de um questionário previamente validado por juízes, que posteriormente foram analisados pelo programa SPSS versão 23.0. Para comparar a variável nível de conhecimento no pós-teste imediato entre os grupos, utilizou-se o teste de MannWhitney e esta mesma variável dentro dos grupos, em relação ao número de acertos, foi avaliada pelo teste de 
Wilcoxon. Resultados: o treinamento de Suporte Básico de Vida foi efetivo na melhora do nível de conhecimento, comparando o pré-teste ao pós-teste imediato $(\mathrm{p}<0,01)$. Entretanto, não houve aumento significante deste no pós-teste imediato entre os estudantes incluídos no grupo 1 em relação ao grupo $2(p=0,12)$. Conclusão: o treinamento em Suporte Básico de Vida, tanto teórico quanto prático, aumentou o nível conhecimento de estudantes do ensino médio sobre essa temática. Reforça-se que ações educativas em saúde sobre essa temática são de extrema relevância nas escolas de ensino médio.

Palavras-chave: Educação básica; Reanimação cardiopulmonar; Educação em saúde; Enfermagem.

\begin{abstract}
Introduction: knowledge of Basic Life Support measures favors assistance in cardiopulmonary arrest, with a view to reducing the mortality rate. Objective: to analyze the effect of training in Basic Life Support for high school students. Methodology: quasi-experimental study, carried out in March 2019, in a federal public education institution, with high school students. Sociodemographic data and questions about knowledge in Basic Life Support were collected from a questionnaire previously validated by judges, which were later analyzed using the SPSS version 23.0 program. To compare the variable level of knowledge in the immediate post-test between the groups, the Mann-Whitney test was used and this same variable within the groups, in relation to the number of correct answers, was evaluated by the Wilcoxon test. Results: Basic Life Support training was effective in improving the level of knowledge, comparing the pre-test to the immediate post-test $(\mathrm{p}<0.01)$. However, there was no significant increase in this in the immediate posttest among students included in group 1 compared to group $2(\mathrm{p}=0.12)$. Conclusion: training in Basic Life Support, both theoretical and practical, increased the level of knowledge of high school students on this topic. It is reinforced that health education actions on this theme are extremely relevant in high schools.
\end{abstract}

Keywords: Basic education; Cardiopulmonary resuscitation; Health education; Nursing.

\title{
Resumen
}

Introducción: el conocimiento de las medidas de Soporte Vital Básico favorece la asistencia en la parada cardiopulmonar, con miras a reducir la tasa de mortalidad. Objetivo: analizar el efecto de la formación en Soporte Vital Básico para estudiantes de secundaria. Metodología: estudio casi-experimental, realizado en marzo de 2019, en una institución de educación pública federal, con estudiantes de secundaria. Los datos sociodemográficos y las preguntas sobre conocimientos en Soporte Vital Básico fueron recolectados a partir de un cuestionario previamente validado por los jueces, que posteriormente fueron analizados mediante el programa SPSS versión 23.0. Para comparar la variable nivel de conocimiento en el post-test inmediato entre los grupos se utilizó la prueba de MannWhitney y esta misma variable dentro de los grupos, en relación al número de aciertos, se evaluó mediante la prueba de Wilcoxon. Resultados: El entrenamiento en Soporte Vital Básico fue efectivo para mejorar el nivel de conocimiento, comparando el pre-test con el post-test inmediato ( $\mathrm{p}<0.01$ ). Sin embargo, no hubo un aumento significativo en esto en la prueba posterior inmediata entre los estudiantes incluidos en el grupo 1 en comparación con el grupo 2 ( $\mathrm{p}=0,12)$. Conclusión: la formación en Soporte Vital Básico, tanto teórico como práctico, incrementó el nivel de conocimiento de los estudiantes de secundaria sobre este tema. Se refuerza que las acciones de educación para la salud en este tema son de suma relevancia en las escuelas secundarias.

Palabras clave: Educación básica; Reanimación cardiopulmonar; Educación para la salud; Enfermería.

\section{Introdução}

Dados epidemiológicos sobre parada cardiorrespiratória (PCR) no Brasil ainda são escassos. Estima-se que a taxa de sobrevida seja em torno de 50 a 70\% quando a desfibrilação é realizada precocemente no ambiente extra-hospitalar e em até 3 a 7 minutos do início da PCR (American Heart Association [AHA], 2020; Bernoche, et al., 2019). Este evento caracteriza-se pela interrupção da circulação sanguínea devido à ausência de atividade ou por funcionamento anormal do coração e respiração, sendo uma das emergências de maior morbimortalidade (AHA, 2015; Assalin, et al., 2019). Neste contexto, a reanimação cardiopulmonar (RCP) precoce e eficaz, realizada por profissionais da saúde ou leigos, é considerada uma ação preditiva mais importante de sobrevida e qualidade de vida a longo prazo em pessoas acometidas por esse evento fora do ambiente hospitalar (Bhanji, et al., 2015).

Estima-se, que a cada minuto em que a vítima deixe de receber as manobras de RCP corretamente, há uma redução de aproximadamente de 7\% a 10\% em sua chance de sobrevida (Gonzalez, et al., 2013). Desta forma, a identificação precoce dos sinais clínicos e a realização das manobras de RCP, com compressões torácicas efetivas, pode colaborar para o aumento de duas a três vezes na chance de sobrevivência de vítimas em ambiente extra-hospitalar (Al-Mohaissen, 2017). Sabendo que 50\% 
dos casos de PCR acontecem em vias públicas, há a necessidade de se estender a capacitação em Suporte Básico de Vida (SBV) ao público leigo, viabilizando o reconhecimento precoce e a realização eficiente das manobras cardíacas (Freire, et al., 2017; Gonzalez, et al., 2013).

O SBV possui etapas que podem ser realizadas fora do ambiente hospitalar, por qualquer pessoa devidamente informada e capacitada, uma vez que executado de maneira precisa, aumentam as chances de sobrevida da vítima (AHA, 2020). Nessa perspectiva, a RCP consiste em uma sequência organizada de manobras, visando o restabelecimento da circulação espontânea com a reversibilidade do processo inicial responsável pelo desencadeamento da PCR (Bernoche, et al., 2019). As manobras de RCP visam manter artificialmente o fluxo sanguíneo arterial ao cérebro e a outros órgãos vitais, até que se restabeleça o retorno da circulação espontânea e homeostase (Tallo, et al., 2012).

Dentre a população leiga que desconhece as manobras de RCP, estão os adolescentes e crianças, entretanto, o treinamento em SBV não é uma realidade nas escolas brasileiras. Reconhece-se que as escolas representam um lugar ideal para atividades teórico-práticas, o que justifica a necessidade de qualificar e potencializar o ensino de temáticas sobre saúde nestes ambientes. É notável na literatura o desenvolvimento de estudos que investiguem o conhecimento de estudantes referente aos aspectos relativos à saúde, além de reforçarem a importância da realização de novas pesquisas sobre a temática em ambientes educacionais, especialmente envolvendo SBV (Nogueira, et al., 2020; Machado Filho, et al., 2021; Maigret, et al., 2021; Mior, et al., 2020; Paim, et al., 2021; Silva, et al., 2021). Os adolescentes possuem capacidade para a fixação de conhecimentos teóricos e práticos, e são potenciais testemunhas de uma PCR (Connolly, et al., 2007; Santos et, al., 2021). Além disso, o conhecimento da população leiga acerca da PCR e da cadeia de reanimação é de extrema importância a fim de otimizar o tempo de chegada no serviço emergência, aumentando assim, a sobrevida do paciente (Dixe \& Gomes, 2015).

Diante deste cenário, abordar este tema nas práticas de educação em saúde no ambiente escolar torna-se relevante, uma vez que o conhecimento adequado acerca do SBV poderá contribuir para ação efetiva de estudantes frente a uma parada cardiorrespiratória. Assim, o objetivo deste estudo foi analisar o efeito do treinamento em Suporte Básico de Vida para estudantes do ensino médio.

\section{Metodologia}

Trata-se de um estudo piloto, quase experimental, com dois grupos e avaliação pré e pós-intervenção, realizado em uma instituição pública de ensino na região sudoeste de Minas Gerais durante o mês de março de 2019. Foi considerado estudo piloto por ter a finalidade de testar as estratégias de intervenção, recrutamento dos participantes, protocolo de intervenção, coleta e análise de dados (Conn, et al., 2010).

Por se tratar de um estudo piloto, não há uma fórmula ideal para delimitar o tamanho da amostra (Hertzog, 2008). A seleção da amostra ocorreu por conveniência, conforme os seguintes critérios de inclusão: estar regularmente matriculado no ensino médio e presente nas duas etapas da coleta de dados (pré e pós-teste). O critério de exclusão foi possuir algum curso ou formação envolvendo urgência e emergências. Foram elegíveis estudantes do ensino médio dos cursos integrados Técnico em Informática, Técnico em Comunicação Visual e Técnico em Produção de Moda.

Para a coleta de dados, foi utilizado um questionário construído pelos pesquisadores conforme recomendações das Diretrizes de 2015 da American Heart Association (AHA), referentes a última atualização no momento da coleta de dados deste estudo (AHA, 2015; Coluci, et al., 2015) e, em seguida, validado por um comitê de juízes. Os participantes do processo de validação eram enfermeiros, possuíam experiência no atendimento de urgências e emergências há mais de 12 meses (préhospitalares e/ou hospitalares) e eram docentes de cursos da área da saúde. 
A versão final do questionário foi composto por duas seções: I- variáveis sociodemográficas (idade, sexo e anos de escolaridade) e II- variáveis relacionadas ao conhecimento sobre SBV, que abrangiam: sinais de possível PCR; condutas iniciais para o reconhecimento de uma PCR; número de telefone que deve ser utilizado para pedir ajuda; informações que devem ser fornecidas ao serviço de emergência quando se liga para pedir ajuda; como se deve posicionar a pessoa que está irresponsiva (inconsciente); número de compressões torácicas aproximadamente que devem ser feitas por minuto quando uma pessoa está em PCR; local de posicionamento das mãos para se realizar as compressões torácicas; sequência de atendimento de uma PCR; sequência correta de uso do desfibrilador externo automático (DEA); procedimento a ser realizado imediatamente após o choque do desfibrilador. Com isso, a seção II foi composta por 10 questões que continham cinco alternativas, e o participante deveria selecionar apenas uma resposta.

Para evitar viés de coleta, as turmas foram abordadas individualmente. Além disso, as perguntas do questionário da medida de conhecimento sobre SBV foram intercaladas para que cada turma recebesse uma versão diferente, a fim de evitar troca de informações entre elas. Os pesquisadores inicialmente aplicaram o questionário de medida do conhecimento sobre SBV e estipularam 20 minutos para retorno com as respostas.

Em seguida, os participantes foram divididos em dois grupos (G1 e G2), com o intuito de avaliar dois métodos de ensino sobre SBV. A divisão dos grupos ocorreu por ordem alfabética a partir de uma lista de presença cedida no momento do treinamento. O G1, foi direcionado ao Laboratório de Enfermagem e recebeu o treinamento prático em RCP, com duração média de 20 minutos. Foi utilizado manequim da marca ANAT ENF SIMULADORES e o desfibrilador externo automático da marca HeartSine Samaritan PAD Trainer, para que as pesquisadoras fizessem a demonstração das técnicas de SBV com as seguintes ações: reconhecimento de uma possível PCR (inspeção do padrão respiratório, abordagem das vias aéreas e palpação de pulso carotídeo) e aplicação de compressões torácicas.

O G2 foi direcionado a uma sala de aula e assistiu uma aula teórica com duração aproximada de 20 minutos sobre SBV corrigida e ajustada por dois professores especialistas em Emergências previamente; em seguida, recebeu o treinamento prático em RCP no laboratório de Enfermagem. Ambos os grupos, finalmente, preencheram o questionário de conhecimento pós-teste imediato. Ambas as intervenções foram padronizadas e ministradas pelas mesmas pesquisadoras.

Os dados coletados foram transferidos para uma planilha do Microsoft Excel 2010®, por meio de dupla digitação. Estatísticas descritivas foram utilizadas para resumir as características sociodemográficas. O teste de Kolmogorov-Smirnov foi utilizado para verificar a distribuição dos dados. Para comparar a mediana do nível de conhecimento e a proporção de acertos antes e após o treinamento, utilizaram-se os testes de Wilcoxon ou Mann-Whitney e McNemar, respectivamente. O nível de significância de 5\% foi considerado. Os dados foram analisados usando o software Statistical Package for the Social Sciences (IBM ® SPSS- versão 23.0).

Após o aceite da instituição participante e aprovação do Comitê de Ética em Pesquisa (CEP) do Instituto Federal do Sul de Minas - IFSULDEMINAS (parecer $\mathrm{n}^{\circ}$ : 3.092.174), os pesquisadores foram ao local de estudo em uma data previamente agendada para realizar o convite aos estudantes, que foram esclarecidos sobre os objetivos da pesquisa e da necessidade de anuência dos seus pais e/ou responsáveis por meio do Termo de Consentimento Livre e Esclarecido (TCLE) e Termo de Assentimento Livre e Esclarecido (TALE) para menores de 18 anos. Além disso, foi acordada entre os estudantes e pesquisadores uma data de devolução deste documento assinado e participação no treinamento. $O$ estudo atendeu às exigências éticas previstas pela Resolução 466/12 do Conselho Nacional de Saúde do Brasil (Brasil, 2012), bem como às recomendações da Declaração de Helsinki. 


\section{Resultados}

Um total de 225 estudantes foram elegíveis para esse estudo. Destes, 47 foram excluídos e um foi descontinuado após a primeira etapa, conforme demonstrado no diagrama de fluxo (Figura 1). Sendo assim, participaram do treinamento 177 estudantes, o que equivale a 78,6\% do total de estudantes convidados. Desse total, 88 estudantes foram alocados no grupo 1 (G1), que recebeu treinamento prático e 89 estudantes foram alocados no grupo 2 (G2), que recebeu treinamento teóricoprático, conforme Figura 1.

Figura 1 - Fluxograma dos participantes.

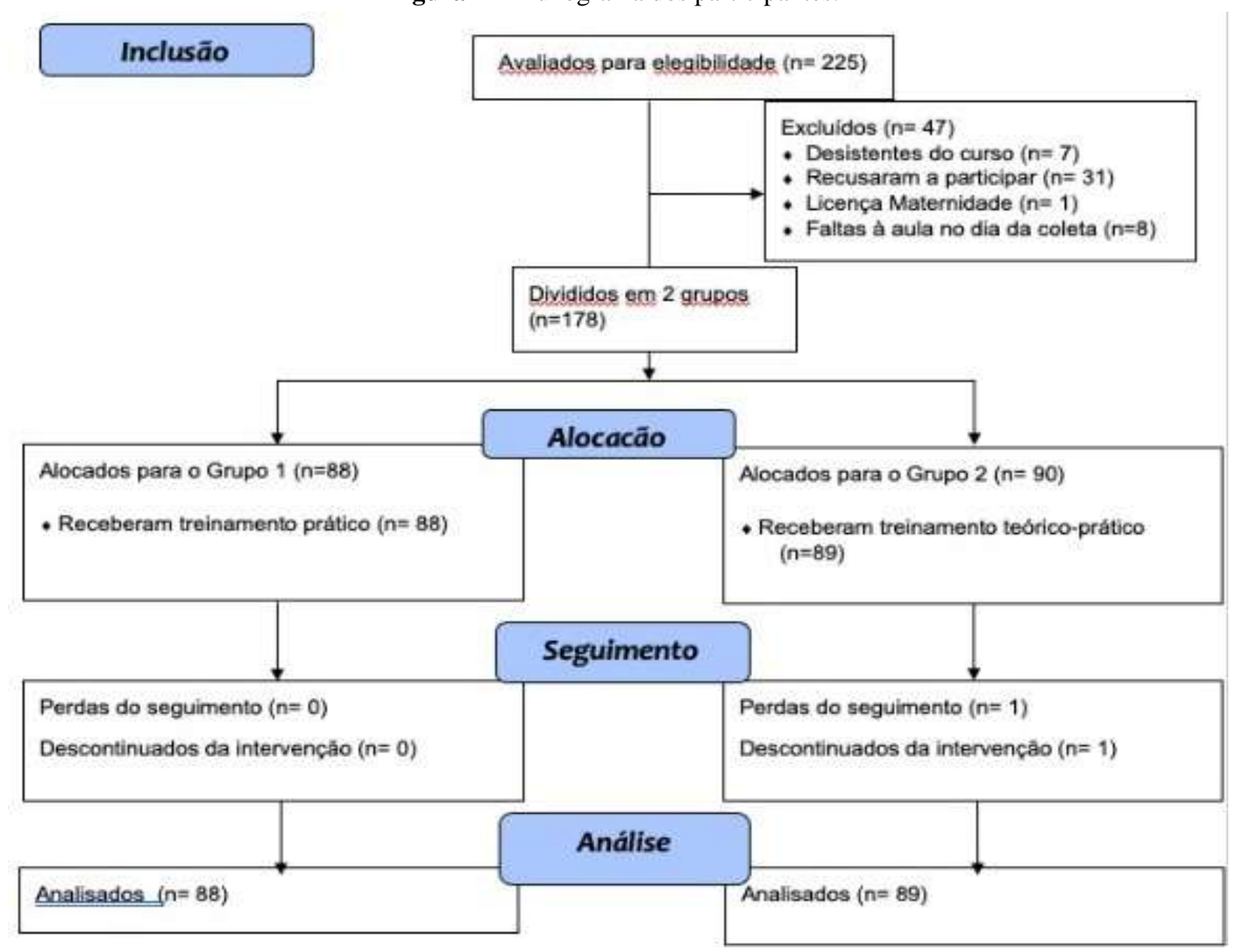

Fonte: Autores (2019).

Dos 177 estudantes que participaram do estudo, 30,5\% (n=54) estavam matriculados no curso Técnico em Comunicação Visual; 33,3\% (n=59) no curso Técnico em Informática e 36,2\% (n=64) no curso Técnico em Produção de Moda. A mediana de idade foi de 15,0 anos ( $\min =11$; máx=18). Quase a totalidade dos participantes eram mulheres $(67,8 \%$; n=120) com mediana de anos de escolaridade de 9 anos (min=9; máx=10). Em relação à experiência prévia de uma situação de emergência, 50,3\% (n=89), afirmaram já ter presenciado alguma situação de PCR. 
Tabela 1 - Caracterização dos estudantes no Curso de Suporte Básico de Vida.

\begin{tabular}{llll}
\hline Características dos estudantes & $\begin{array}{l}\text { G1 } \\
(\mathbf{n = 8 8})\end{array}$ & $\begin{array}{l}\text { G2 } \\
(\mathbf{n = 8 9})\end{array}$ & p valor* \\
\hline Idade (anos), mediana (min-máx) & $15(13-18)$ & $15(14-17)$ & $0,23^{\ddagger}$ \\
Feminino (n), (\%) & $64(72,7)$ & $56(62,9)$ & $0,16^{\ddagger}$ \\
Curso (n), (\%) & & & \\
$\quad$ Técnico em informática & $30(34,1)$ & $29(32,6)$ & \\
$\quad$ Comunicação visual & $26(29,5)$ & $28(31,5)$ & $0,95^{\ddagger}$ \\
$\quad$ Produção de moda & $32(36,4)$ & $32(36,1)$ & \\
Educação (anos), mediana (min-máx) & $9,0(9-10)$ & $9,0(9-10)$ & $1,00^{\S}$ \\
\hline
\end{tabular}

Nota: ${ }^{\ddagger}$ p-valor obtido por meio do teste Qui-quadrado, § p-valor obtido por meio do teste de Mann-Whitney.

Fonte: Autores (2019).

Na Tabela 2, são apresentadas as medianas das respostas dos estudantes no pré e pós-teste imediato sobre SBV a uma vítima adulta em PCR. O conhecimento dos estudantes de ambos os grupos no pós-teste foi significativamente maior que no pré-teste (medianas 8,0 e 9,0 , respectivamente; $\mathrm{p}<0,01$ ).

Tabela 2 - Comparação do nível de conhecimento no pré-teste e pós-teste imediato no curso de Suporte Básico de Vida.

\begin{tabular}{cccc}
\hline & Pré-teste & Pós-teste imediato & p-valor* \\
\cline { 2 - 3 } & mediana (min-max) & mediana (min-max) & \\
\hline Soma de acertos G1 & $6,0(2,0-9,0)$ & $8,0(6,0-10,0)$ & $<, 01$ \\
\hline Soma de acertos G2 & $6,0(4,0-8,0)$ & $9,0(6,0-10,0)$ & $<\mathbf{0 , 0 1}$ \\
\hline p-valor** & $\mathbf{0 , 4 1}$ & $\mathbf{0 , 1 2}$ & - \\
\hline
\end{tabular}

*p-valor obtido por meio do teste de Wilcoxon.

**p-valor obtido por meio do teste de Mann-Whitney.

Fonte: Autores (2019).

Na Tabela 3, são apresentadas as proporções de acertos dos estudantes envolvendo o SBV. Por meio do teste de McNemar, quando comparadas as proporções no pré e pós-teste, observou-se diferença estatisticamente significante na questão 1 (São sinais de uma possível parada cardiorrespiratória) ( $<<0,001$ ); questão 3 (Quando você identifica uma situação de emergência, qual é o número do telefone que deve ser utilizado corretamente para pedir ajuda?) (p<0,001); questão 5 (Como se deve posicionar a pessoa que está irresponsiva (inconsciente)?) $(\mathrm{p}<0,001)$; questão 7 (Qual deve ser o local de posicionamento das mãos para se realizar as compressões torácicas?) $($ p<0,001) e questão 8 (Em relação ao atendimento à pessoa em parada cardiorrespiratória, assinale a sequência correta de atendimento) ( $\mathrm{p}<0,001)$. Com isso, é possível notar que apenas as questões que envolviam os elos inicias da cadeia de sobrevivência - acionamento do serviço de urgência/emergência e a realização da RCP - apresentaram aumento do número de acertos estatisticamente significante. 
Tabela 3 - Distribuição das respostas corretas dos estudantes antes e após intervenção.

\begin{tabular}{|c|c|c|c|c|c|c|}
\hline \multirow{3}{*}{ Questões } & \multicolumn{3}{|c|}{ G1 } & \multicolumn{3}{|c|}{ G2 } \\
\hline & Pré-teste & $\begin{array}{l}\text { Pós-teste } \\
\text { imediato }\end{array}$ & p-valor* & Pré-teste & $\begin{array}{l}\text { Pós-teste } \\
\text { imediato }\end{array}$ & p-valor* \\
\hline & n $(\%)$ & n $(\%)$ & & n $(\%)$ & n $(\%)$ & \\
\hline $\begin{array}{l}\text { 1-São sinais de uma possível parada } \\
\text { cardiorrespiratória: }\end{array}$ & $76(86,4)$ & $87(98,9)$ & $<0,001$ & $73(81,1)$ & $88(98,9)$ & $<0,001$ \\
\hline $\begin{array}{l}\text { 2-São condutas iniciais para reconhecimento de } \\
\text { uma parada cardiorrespiratória, exceto: }\end{array}$ & $54(61,4)$ & $56(63,6)$ & 0,15 & $60(66,7)$ & $61(68,5)$ & 0,10 \\
\hline $\begin{array}{l}\text { 3-Quando você identifica uma situação de } \\
\text { emergência, qual é o número do telefone que } \\
\text { deve ser utilizado corretamente para pedir ajuda? }\end{array}$ & $29(32,9)$ & $72(81,8)$ & $<0,001$ & $39(43,3)$ & $72(80,9)$ & $<0,001$ \\
\hline $\begin{array}{l}\text { 4-Quais são as informações que você deve } \\
\text { fornecer pelo telefone ao serviço de emergência } \\
\text { quando você ligar para pedir ajuda? }\end{array}$ & $86(97,7)$ & $87(98,9)$ & 1,00 & $88(97,8)$ & $88(98,9)$ & 1,00 \\
\hline $\begin{array}{l}\text { 5-Como se deve posicionar a pessoa que está } \\
\text { irresponsiva (inconsciente)? }\end{array}$ & $44(50,0)$ & $86(97,7)$ & $<0,001$ & $45(50,0)$ & $88(98,9)$ & $<0,001$ \\
\hline $\begin{array}{l}\text { 6- Quando uma pessoa está em parada } \\
\text { cardiorrespiratória, quantas compressões } \\
\text { torácicas devem ser realizadas por minuto? }\end{array}$ & $24(27,3)$ & $54(61,4)$ & $<0,001$ & $18(20,0)$ & $60(67,4)$ & $<0,001$ \\
\hline $\begin{array}{l}\text { 7-Qual deve ser o local de posicionamento das } \\
\text { mãos para se realizar as compressões torácicas? }\end{array}$ & $61(69,3)$ & $87(98,9)$ & $<0,001$ & $60(66,7)$ & $87(97,7)$ & $<0,001$ \\
\hline $\begin{array}{l}\text { 8-Em relação ao atendimento à pessoa em parada } \\
\text { cardiorrespiratória, assinale a sequência correta } \\
\text { de atendimento: }\end{array}$ & $46(52,3)$ & $80(90,9)$ & $<0,001$ & $51(56,7)$ & $81(81,1)$ & $<0,001$ \\
\hline $\begin{array}{l}\text { 9-Em relação ao desfibrilador externo automático } \\
\text { - DEA, assinale a alternativa que compreende a } \\
\text { sequência correta de sua utilização: }\end{array}$ & $44(50,0)$ & $60(68,2)$ & 0,26 & $49(54,4)$ & $68(76,4)$ & 0,03 \\
\hline $\begin{array}{l}\text { 10-Imediatamente após o choque do } \\
\text { desfibrilador, qual o procedimento que devemos } \\
\text { seguir: }\end{array}$ & $64(72,7)$ & $65(73,9)$ & 0,87 & $68(75,5)$ & $71(79,8)$ & 0,66 \\
\hline
\end{tabular}

*p-valor obtido por meio do teste de McNemar

Fonte: Autores (2019).

\section{Discussão}

Esta pesquisa objetivou analisar o efeito do treinamento em Suporte Básico de Vida para estudantes do ensino médio. Mais da metade dos estudantes (50,3\%) afirmaram já terem presenciado uma situação de emergência, o que reforça a importância da abordagem dessa temática na escola, uma vez que em média metade dos casos de PCR ocorrem em ambiente extra-hospitalar e podem acometer de forma inesperada qualquer pessoa (Gonzalez, et al., 2013; Landa \& Ferreira, 2020). Assim, o ensino do SBV para essa população deve ser visto como prioridade, uma vez que o atendimento precoce representa um fator decisivo para a sua sobrevivência. A necessidade de inserção de atividades, capacitações teóricas e práticas sobre o SBV também são vistas como ações necessárias para a otimização e consolidação do conhecimento entre estudantes de cursos de graduação na área da saúde, conforme os achados de estudos recentes (Nogueira, et al., 2020; Silva, et al., 2021).

Este estudo proporcionou que os participantes alcançassem níveis elevados de conhecimento imediatamente após receberem as intervenções educativas de SBV. Resultados semelhantes foram encontrados em estudos realizados com alunos do ensino médio na Arábia Saudita, Jordânia e no Brasil, onde foram identificados baixo conhecimento prévio de estudantes 
quanto ao atendimento em PCR, no entanto, após intervenção educativa, os participantes apresentaram incremento significante de conhecimentos e habilidades adquiridos (Aloush, et al., 2019; Fernandes, et al., 2014; Magadi, et al., 2018).

No presente estudo, algumas questões que envolviam os elos inicias da cadeia de sobrevivência como itens 1, 3, 5, 6, 7 e 8 (AHA, 2015) apresentaram aumento significante $(\mathrm{p}<0,001)$ no pós-teste para ambos os grupos. Estudo norte americano, identificou que a RCP representa um elo vital na cadeia de sobrevivência, o que justifica mais uma vez, a necessidade de programas de treinamentos em RCP nas escolas, caracterizando-se uma necessidade de âmbito mundial (Hoyme \& Atkins, 2017). Além disso, a atualização recente da AHA, recomenda que os leigos iniciem a RCP mesmo em caso de uma suposta PCR, justificando que o risco de dano se configura baixo se a vítima não estiver em PCR (AHA, 2020).

Para a AHA, o fornecimento de compressões torácicas de alta qualidade é vital para uma RCP bem sucedida (AHA, 2020). Neste estudo, as respostas dos estudantes relacionadas a quantidade dessas compressões por minuto apresentaram uma melhora considerável após a intervenção, os acertos evoluíram de 27,3\% para 61,4\% no grupo 1 e de $20 \%$ para $67,4 \%$ no grupo 2, ambos com $\mathrm{p}<0,001$. Essa evolução também foi encontrada em estudo recente desenvolvido com estudantes do ensino médio de uma escola pública, cujo o conhecimento sobre as compressões torácicas apresentou diferença significativa, de $59,2 \%$ para $82,3 \%$ no pós-teste (Nunes, et al., 2021).

Em contrapartida, nas questões relacionadas aos terceiros e quartos elos da cadeia de sobrevivência (itens 9 e 10), apenas o G2 apresentou um melhor resultado $(54,4 \%$ para 76,4\%) no que se refere à sequência correta de utilização do DEA (questão 9); este achado pode estar relacionado ao recebimento da combinação do treinamento teórico e prático. Nesta mesma perspectiva, em um estudo conduzido com estudantes universitários dos primeiros períodos e leigos em SBV, também pode-se verificar o incremento no desempenho dos alunos após treinamento teórico, porém com índice de acertos inferior a 90\%; entretanto, após treinamento prático, observou-se aumento do conhecimento superior a 90\%, evidenciando a importância da associação dos treinamentos teórico e prático (Kawakame \& Miyadahira, 2015). Em nosso estudo, a associação da teoria com a prática pode contribuir para o manuseio correto do DEA, uma vez que o estudante teve contato com conhecimento teóricoprático para a utilização do desfibrilador, e não apenas com as instruções fornecidas pelo próprio aparelho.

Em relação aos tipos de intervenções ofertadas, por meio do treinamento prático ou teórico-prático, não se verificou uma diferença significativa na evolução das repostas entre os grupos. Contudo, como descrito anteriormente na literatura, este estudo aguçou a percepção dos pesquisadores acerca de uma ligeira vantagem do grupo teoria/prática em relação ao grupo prática, ratificando a importância da associação da teoria com a prática no processo de ensino do SBV (Fernandes, et al., 2014).

Torna-se imprescindível a qualificação dos estudantes em manobras e procedimentos envolvendo RCP, porém essa realidade ainda se apresenta distante em alguns países, incluindo o Brasil, devido à existência de barreiras para a sua implementação no contexto escolar (Fernandes, et al., 2014; Hoyme \& Atkins, 2017). A capacitação de leigos, além de representar uma das diretrizes preconizadas pela AHA (2015), deve ser vista como uma temática fundamental a ser considerada no ensino das escolas brasileiras, com intuito de proporcionar incremento do conhecimento acerca do SBV entre estudantes e professores. Destaca-se a necessidade de inserção de ações de promoção de saúde no ambiente escolar, em especial, o SBV, com intuito de instrumentalizar estudantes para a tomada de decisões eficazes durante a ocorrência de situações de emergência e aumentar a possibilidade de disseminação de conhecimento.

O ambiente escolar é propício às ações educativas em saúde, assim, além das universidades, serviços ou profissionais de saúde, alunos e professores também precisam ser capacitados, a fim de que seja efetivada a promoção da saúde escolar. Tais ações tornam-se importantes, principalmente para estudantes de faixas etárias entre 15 e 18 anos, assim, à medida que esses são capacitados, tornar-se-ão aptos para atendimento básico em PCR, com vistas à redução na taxa de mortalidade precoce por doenças cardiovasculares, as quais podem ser evitadas com atendimento imediato e efetivo. Nesse contexto, o enfermeiro pode 
ter um papel primordial na educação desta população acerca do SBV, com intuito de contribuir para um atendimento qualificado em RCP. Além do mais, acredita-se que a capacidade de aprendizagem e disseminação do conhecimento podem ser mais efetivas no ambiente escolar.

\section{Conclusão}

Frente ao exposto, conclui-se que o treinamento em SBV, tanto prático quanto teórico-prático, foi capaz de aumentar o nível de conhecimento geral de estudantes do ensino médio sobre essa temática. Porém, ainda há lacunas sobre qual é o melhor método para esse tipo de treinamento, havendo a necessidade da condução de novos estudos. Reforça-se que ações educativas em saúde sobre essa temática são de extrema relevância em escolas de ensino médio.

\section{Referências}

Al-Mohaissen, M. A. (2017). Knowledge and attitudes towards basic life support among health students at a Saudi women's university. Sultan Qaboos University Medical Journal, 17(1) e59. doi: 10.18295/squmj.2016.17.01.011.

Aloush, S., Tubaishat, A., ALBashtawy, M., Suliman, M., Alrimawi, I., Al Sabah, A., \& Banikhaled, Y. (2019). Effectiveness of Basic Life Support Training for Middle School Students. The Journal of School Nursing, 35(4), 262-267. https://doi.org/10.1177/1059840517753879.

American Heart Association (2020). Destaques das Diretrizes de RCP e ACE de 2020 da American Heart Association. https://cpr.heart.org/ /media/cprfiles/cpr-guidelines-files/highlights/hghlghts_2020eccguidelines_portuguese.pdf.

American Heart Association. (2015). Destaques das Diretrizes da American Heart Association 2015 para RCP e ACE. https://cpr.heart.org/-/media/cprfiles/cpr-guidelines-files/highlights/hghlghts_2020eccguidelines_portuguese.pdf.

Assalin, A. C. B., Oliveira, L. N., Souza, A. R., Grazziano, E. S., \& Machado, R. C. (2019). An In Loco Theoretical and Practical Training Program for Nursing Professionals Regarding the Basic Maneuvers in Cardiopulmonary Resuscitation/Programa de Treinamento Teórico/Prático InLoco para Enfermagem Acerca das Manobras Básicas em Ressuscitação Cardiopulmonar. Revista de Pesquisa Cuidado é Fundamental Online, 11(2), 495-501. https://doi.org/10.9789/2175-5361.2019.v11i2.495-501.

Bernoche, C., Timerman. S., Polastri, T. F., Giannetti, N. S., Siqueira, A. W. S., Piscopo, A., \& Sako, Y. K. (2019). Atualização da Diretriz de Ressuscitação Cardiopulmonar e Cuidados Cardiovasculares de Emergência da Sociedade Brasileira de Cardiologia - 2019. Arquivos Brasileiros de Cardiologia, 113(3), 449- 663. http://dx.doi.org/10.5935/abc.20190203.

Bhanji, F., Donoghue, A. J., Wolff, M. S., Flores, G. E., Halamek, L. P., Berman, J. M., Sinz, E. H. \& Cheng, A. (2015). Part 14: education: 2015 American Heart Association guidelines update for cardiopulmonary resuscitation and emergency cardiovascular care. Circulation, 132(18_suppl_2), 561-573. https://doi.org/10.1161/CIR.0000000000000268.

Brasil. (2012). Ministério da Saúde. Conselho Nacional de Saúde. http://bvsms.saude.gov.br/bvs/saudelegis/cns/2013/res0466_12_12_2012.html.

Coluci, M. Z. O., Alexandre, N. M. C., \& Milani, D. (2015). Construction of measurement instruments in the area of health. Ciência \&. Saúde Coletiva., 20(3), 925-936. https://doi.org/10.1590/1413-81232015203.04332013.

Conn, V. S., Algase, D. L., Rawl, S. M., Zerwic, J. J., \& Wyman, J. F. (2010). Publishing pilot intervention work. Western Journal of Nursing Research, 32(8), 994 -1010. https://doi.org/10.1177/0193945910367229.

Connolly, M., Toner, P., Connolly, D., \& McCluskey, D. R. (2007). The 'ABC for life'programme-teaching basic life support in schools. Ressuscitation, 72(2), 270-279. https://doi: 10.1016/j.resuscitation.2006.06.031. Epub 2006 Nov 28.

Dixe, M. D. A. C. R., \& Gomes, J. C. R. (2015). Knowledge of the Portuguese population on Basic Life Support and availability to attend training. Revista da Escola de Enfermagem da USP, 49, 0640-0649. http://10.1590/S0080-623420150000400015.

Fernandes, J. M. G., Leite, A. L. D. S., Auto, B. D. S. D., Lima, J. E. G. D., Rivera, I. R., \& Mendonça, M. A. (2014). Ensino de suporte básico de vida para alunos de escolas pública e privada do ensino médio. Arquivos Brasileiros de Cardiologia, 102(6), 593-601. https://doi.org/10.5935/abc.20140071.

Freire, I. L. S., dos Santos, F. R., do Nascimento, A. C., de Medeiros, A., da Silva, B. C., \& Cavalcante, C. A. (2017). Validation of questionnaire for the evaluation of knowledge of nursing teachers and students on the basic life support. Journal of Nursing UFPE, 11(12),4953-4960.https://doi.org/10.5205/19818963-v11i12a23556p4953-4960-2017.

Gonzalez, M. M., Timerman, S., de Oliveira, R. G., Polastri, T. F., Dallan, L. A. P., Araújo, S., Lage, S. G., Schmidt, A., Bernoche, C. S. M. I., Carnesin, M. F., Mancuso, F. J. N \& Favarato, M. H. (2013). I Diretriz de ressuscitação cardiopulmonar e cuidados cardiovasculares de emergência da Sociedade Brasileira de Cardiologia: resumo executivo. Arquivos Brasileiros de Cardiologia, 100(2), 105-113. https://doi.org/10.5935/abc.20130022.

Hertzog, M. A. (2008). Considerations in determining sample size for pilot studies. Research in Nursing \& Health, 31(2), 180-191. https://doi.org/10.5935/abc.20130022.

Hoyme, D. B., \& Atkins, D. L. (2017). Implementing cardiopulmonary resuscitation training programs in high schools: Iowa's experience. The Journal of Pediatrics, 181, 172-176. https://doi.org/10.1016/j.jpeds.2016.10.037. 
Kawakame, P. M. G., \& Miyadahira, A. M. K. (2015). Avaliação do processo ensino-aprendizagem de estudantes da área da saúde: manobras de ressuscitação cardiopulmonar. Revista da Escola de Enfermagem da USP, 49(4), 657-664. https://doi.org/10.1590/S0080-623420150000400017.

Landa, J., \& Ferreira, A. M. G. B. (2020). Transferência do Conhecimento de Suporte Básico de Vida para Leigos e Profissionais de Saúde: uma Revisão Integrativa. Revista Brasileira Multidisciplinar, 23(2Supl.), 99-114. https://doi.org/10.25061/2527-2675/ReBraM/2020.v23i2Supl..810.

Machado Filho, M. da M., Ávila, M. C. do N., Cunha, F. I. J., \& Pessano, E. F. C. (2021). A relação Meio Ambiente e Saúde através das concepções de estudantes e professores(as) dos anos finais do Ensino Fundamental. Research, Society and Development, 10(3), e59710314261. https://doi.org/10.33448/rsdv10i3.14261.

Magadi, K. H., Alharbi, M. F., Soliman, A. T., \& Alashmawy, M. A. (2018). Knowledge and skills of hands-only cardiopulmonary resuscitation training among secondary school students: An interventional study. Journal of Education, Health and Sport, 8(9), 294-300. http://dx.doi.org/10.6084/m9.figshare.6988685.

Maigret, S. B., Minharro, M. C. O., \& Alencar, R. A. (2021). Estratégias de ensino da simulação do Suporte Básico de Vida em Enfermagem: Uma revisão integrativa. Research, Society and Development, 10(9), e47310918325. https://doi.org/10.33448/rsd-v10i9.18325.

Mior, C. C., Cargnin, M. C. dos S., \& Cargnin, L. (2020). Conhecimento de professores e funcionários sobre primeiros socorros em ambiente escolar: uma pesquisa quase experimental. Research, Society and Development, 9(10), e2239108427. https://doi.org/10.33448/rsd-v9i10.8427.

Nogueira, M. de A., Lins, M. A., Abreu, E. S. de., Pantoja, J. da S., Rodrigues, W. C. C., Bezerra, C. L., Costa, R. E. A. R. da, Rodrigues, M. da G., Rodrigues, R. de S., Silva, F. S. da., Oliveira, K. M. F. de., Pinheiro, G. N., Menezes, I. M. de., Amaral, A. da S. P., Maciel, T. A. F., Carvalho, D. de N. R. de., Aguiar, V. F. F. de., Teixeira, O. N., \& Sá, A. M. M. (2020). Conhecimento dos alunos concluintes do curso de graduação em Enfermagem sobre suporte básico de vida. Research, Society and Development, 9(11), e1349118988. https://doi.org/10.33448/rsd-v9i11.8988.

Nunes, L. M., Frota, M. K. R., Fernandes, M. A. M., Almeida, T. P. D., Sousa, T. M. L. D., \& Fernandes, C. R. (2021). Avaliação de conhecimentos de estudantes do ensino médio acerca da cadeia de sobrevivência em suporte básico de vida antes e após treinamento teórico-prático. Revista de Medicina da UFC, 61, 1, 1-7. http://www.repositorio.ufc.br/handle/riufc/57676.

Paim, M. G., Goldschmidt, A. I., \& Loreto, E. L. da S. (2021). Concepções prévias de alunos do 9o ano do Ensino Fundamental sobre o processo de cicatrização e sua relação com a Biologia Celular. Research, Society and Development, 10(8), e10610817000. https://doi.org/10.33448/rsd-v10i8.17000.

Santos, N. S., de Almeida Santos, G., de Sousa Macedo, L. F. M., da Cruz Freitas, J., \& de Freitas, A. C. (2021). Percepção de Alunos do Ensino Médio sobre Primeiros Socorros. Research, Society and Development, 10(7), e15110715465-e15110715465. https://doi.org/10.33448/rsd-v10i7.15465.

Silva, L. F. X. da, Morais Filho, L. A., Souza, T. A. de, Medeiros, N. T. A. C. de, Matos, J. H. F. de, Silva, J. D. A., Barbosa, Y. M. M., Nascimento, A. K. de F., Camargo, S. R. V., \& Ferreira, J. N. da S. (2021). Conhecimento dos estudantes da saúde sobre suporte básico de vida na parada cardiorrespiratória. Research, Society and Development, 10(7), e21310715277. https://doi.org/10.33448/rsd-v10i7.15277.

Tallo, F. S., Moraes Júnior, R., Guimarães, H. P., Lopes, R. D., \& Lopes, A. C. (2012). Atualização em reanimação cardiopulmonar: uma revisão para o clínico. Revista da Sociedade Brasileira de Clínica Médica, 10(3), 194-200. http://files.bvs.br/upload/S/1679-1010/2012/v10n3/a2891.pdf. 